\title{
Intravitreal ranibizumab for symptomatic drusenoid pigment epithelial detachment without choroidal neovascularization in age-related macular degeneration
}

\author{
This article was published in the following Dove Press journal: \\ Clinical Ophthalmology \\ 7 February 2011 \\ Number of times this article has been viewed
}

\author{
Roberto Gallego-Pinazo ${ }^{1,2}$ \\ Ana Marina \\ Suelves-Cogollos' \\ Ester Francés-Muñoz ${ }^{1}$ \\ J María Millán ${ }^{2,3}$ \\ J Fernando Arevalo ${ }^{4}$ \\ J Luis Mullor ${ }^{5}$ \\ Manuel Díaz-Llopis 1,2,6 \\ 'Department of Ophthalmology, \\ Hospital Universitario La Fe, Valencia, \\ Spain; ${ }^{2}$ Centro de Investigación \\ Biomédica en Red de Enfermedades \\ Raras, Valencia, Spain; ${ }^{3}$ Department \\ of Genetics, Hospital Universitario \\ La Fe, Valencia, Spain; ${ }^{4}$ Retina and \\ Vitreous Service, Clínica Oftalmológica \\ Centro Caracas, Caracas, Venezuela; \\ ${ }^{5}$ Unit of Experimental Ophthalmology, \\ Fundación para la Investigación del \\ Hospital Universitario La Fe, Valencia, \\ Spain; 'University of Valencia, Faculty \\ of Medicine, Valencia, Spain
}

Correspondence: Roberto Gallego-Pinazo Avenida Campanar 21,

Valencia 46009, Spain

Tel +34 659954094

Email robertogallego@comv.es
Background: The aim of our study was to evaluate the functional and anatomic outcomes of intravitreal ranibizumab for the treatment of symptomatic drusenoid pigment epithelial detachment without choroidal neovascularization in age-related macular degeneration.

Methods: This was a prospective, single-center, uncontrolled, interventional pilot study. Six consecutive eyes (six patients) with drusenoid pigment epithelial detachment with a visual acuity of 20/63 to 20/100 and no evidence of choroidal neovascularization in age-related macular degeneration participated. Patients were given at least one intravitreal ranibizumab injection and were followed for a mean of $66.67 \pm 10.3$ weeks. Main outcome measures included best-corrected visual acuity (BCVA) measured by Early Treatment Diabetic Retinopathy Study charts and optical coherence tomography, and central macular thickness measured by optical coherence tomography.

Results: The mean number of intravitreal ranibizumab injections was 3.0 at the end of follow-up. Regarding BCVA and optical coherence tomography, 33.3\% of eyes gained between 19 and 21 letters of BCVA, with a median decrease in central macular thickness of $21 \mu \mathrm{m}$. There was a statistically significant difference between baseline and final BCVA $(P=0.046)$. There was a positive correlation between intraretinal fluid by optical coherence tomography and improved BCVA after intravitreal ranibizumab. Metamorphopsia disappeared completely after the first injection in all subjects, with no further recurrences. No patient developed choroidal neovascularization or atrophic changes.

Conclusion: Intravitreal ranibizumab demonstrated anatomic and functional benefit in patients with symptomatic drusenoid pigment epithelial detachment without choroidal neovascularization in age-related macular degeneration. Further long-term, randomized, controlled trials should be performed to confirm our preliminary results.

Keywords: age-related macular degeneration, choroidal neovascularization, drusenoid pigment epithelial detachment, ranibizumab, soft drusen

\section{Introduction}

Detachment of the retinal pigment epithelium is a common manifestation of age-related macular degeneration. It can be classified as fibrovascular, serous, hemorrhagic, and drusenoid. ${ }^{1,2}$ Drusenoid pigment epithelial detachment appears as a result of the slow coalescence of soft drusen, and it has been distinguished from the other types of pigment epithelial detachment by its relatively better prognosis. ${ }^{3-6}$ However, the natural history usually follows a progression to persistent drusenoid pigment epithelial detachment, geographic atrophy, and neovascularization., ${ }^{7,8}$ 
No treatment has been standardized for drusenoid pigment epithelial detachment. Oral antioxidant supplementation intake is the only treatment suggested to reduce the incidence of geographic atrophic and neovascular complications in patients with soft drusen and dry age-related macular degeneration. ${ }^{8}$ Macular laser photocoagulation to reduce drusen has been used with variable, controversial, and contradictory results. ${ }^{10-13}$ The use of verteporfin photodynamic therapy ${ }^{14}$ or intravitreal pegaptanib ${ }^{15}$ has been reported in drusenoid pigment epithelial detachment, resulting in secondary atrophy with poor visual outcomes. In the same way, a recent report informed about the favorable outcomes of the use of intravitreal bevacizumab, with visual recovery in three cases. ${ }^{16}$ The objective of this pilot study was to evaluate the functional and anatomic outcomes of intravitreal ranibizumab for the treatment of symptomatic drusenoid pigment epithelial detachment without choroidal neovascularization in age-related macular degeneration.

\section{Patients and methods}

This prospective, single-center, uncontrolled, interventional pilot study was conducted at the University Hospital La Fe, Valencia, Spain. Approval was obtained from the Institutional Ethics Committee, and informed consent was obtained for this study. In addition, the study was performed in accordance with the ethical standards laid down in the 1964 Declaration of Helsinki. The off-label use of the drug for this indication, and its potential risks and benefits, were discussed extensively with all patients.

Eligible subjects were at least 50 years of age. Eligibility criteria for a study eye included the following: Early Treatment Diabetic Retinopathy Study (ETDRS) best-corrected visual acuity (BCVA) lower than 20/30; drusenoid pigment epithelial detachment from age-related macular degeneration defined clinically as a focal area of at least $1 / 2$ disc diameter of confluent soft drusen under the center of the macula with faint hypofluoresecence in the early frames of the fluorescein angiogram which increased progressively but stabilized in the late phases, without leakage, and defined tomographically as a focal elevation of the retinal pigment epithelium contour associated with fluid beneath the elevation but without coexistent shadowing; and presence of metamorphosia. Exclusion criteria included angiographic evidence of choroidal neovascularization; prior treatment with photodynamic therapy, intravitreal corticosteroids, or vascular endothelial growth factor inhibitors (at any time); peribulbar steroid injection (within the previous six months) or pars plana vitrectomy (at any time); history of uncontrolled glaucoma; retinal vascular disorder potentially related to macular edema; and intraocular pressure of $25 \mathrm{mmHg}$ or more.

At baseline and at each follow-up visit, ETDRS BCVA letter score was measured. After pupil dilatation, optical coherence tomography images were obtained at baseline and at each follow-up visit using spectral-domain optical coherence tomography (Cirrus High-Definition OCT, Carl Zeiss Meditec, Dublin, CA). The scans employed included a Macular Cube $512 \times 128$, performing two scans and using the average of the two central subthreshold thicknesses for the analysis, and five radial lines to obtain high-resolution images of the study eye. Additional testing included slit-lamp examination, dilated fundus examination, posterior pole retinography, and measurement of intraocular pressure with a pneumotonometer. Subjects were asked to report the main symptoms they were complaining of. The presence of metamorphopsia was assessed by the red-lined black Amsler grid as described in previous reports. ${ }^{17}$ Fluorescein angiography was performed at baseline, and it was repeated only when there was a decrease in BCVA and/or fundus examination or optical coherence tomography findings suggested choroidal neovascularization.

At baseline, every patient underwent a single intravitreal injection of $0.5 \mathrm{mg} / 0.05 \mathrm{~mL}$ of ranibizumab (Lucentis ${ }^{\circledR}$, Genentech, South San Francisco, CA). The intravitreal injection of ranibizumab followed a standardized protocol. Using topical anesthesia followed by a povidone-iodine preparation, ranibizumab was injected into the vitreous cavity $4.0 \mathrm{~mm}$ posterior to the limbus in the inferotemporal quadrant. After the injection, povidone-iodine was dropped again into the conjunctival fornix and topical gentamicin ointment was applied.

Patients were scheduled for monthly follow-up. Retreatment criteria included persistence or recurrence of focal elevation of the retinal pigment epithelium contour on optical coherence tomography, persistence or recurrence of intraretinal fluid on optical coherence tomography, or loss of more than five ETDRS letters when compared with the prior examination.

\section{Results}

The study period was from December 2007 to December 2008 , and six consecutive subjects (mean age \pm standard deviation [SD], $69 \pm 2.9 ; 66.7 \%$ women) were enrolled, all of them with one eye affected with drusenoid pigment epithelial detachment. At baseline, the mean BCVA in the study eyes was $0.40 \pm 0.15$ [decimal ETDRS equivalent] and the mean central macular thickness was $287.83 \pm 23.25 \mu \mathrm{m}$. Additional demographic characteristics of the six subjects are reported in Table 1. The mean follow-up duration for the study was $66.67 \pm 10.3$ (median 68.5, range 52-80) weeks. 
Table I Baseline subject characteristics

\begin{tabular}{|c|c|c|c|c|c|c|c|c|}
\hline \multirow[t]{2}{*}{ Subject } & \multirow[t]{2}{*}{ Age } & \multirow[t]{2}{*}{ Gender } & \multicolumn{3}{|c|}{ Baseline BCVA } & \multirow[t]{2}{*}{ CMT } & \multirow[t]{2}{*}{ Lens } & \multirow[t]{2}{*}{ Visual symptoms } \\
\hline & & & Snellen & Letters & Decimal & & & \\
\hline 1 & 73 & Female & $20 / 63$ & 26 & 0.32 & 286 & Pseudoaphakic & $\begin{array}{l}\text { Blurred vision } \\
\text { and metamorphopsia }\end{array}$ \\
\hline 2 & 71 & Female & $20 / 63$ & 28 & 0.32 & 269 & Phakic & Metamorphopsia \\
\hline 3 & 67 & Male & $20 / 50$ & 33 & 0.4 & 315 & Phakic & $\begin{array}{l}\text { Blurred vision } \\
\text { and metamorphopsia }\end{array}$ \\
\hline 4 & 65 & Female & $20 / 32$ & 42 & 0.63 & 273 & Phakic & Metamorphopsia \\
\hline 5 & 70 & Male & $20 / 40$ & 37 & 0.5 & 266 & Pseudoaphakic & $\begin{array}{l}\text { Blurred vision } \\
\text { and metamorphopsia }\end{array}$ \\
\hline 6 & 68 & Female & $20 / 100$ & 19 & 0.2 & 318 & Phakic & $\begin{array}{l}\text { Blurred vision } \\
\text { and metamorphopsia }\end{array}$ \\
\hline
\end{tabular}

Abbreviations: BCVA, best-corrected visual acuity; CMT, central subfield thickness.

All eyes received intravitreal ranibizumab at baseline. After this first injection, the mean number of retreatments was 2.0 at the end of follow-up. One (16.6\%) patient showed stabilization of the retinal pigment epithelium contour by optical coherence tomography and absence of symptoms after one intravitreal ranibizumab injection through 67 weeks of follow-up and required no retreatment. One (16.6\%) patient required one retreatment at week 24 because of recurrence with a total of 52 weeks of follow-up. Two (33.3\%) patients required two retreatments with 58 (at weeks 12 and 36) and 73 (at weeks 16 and 44) weeks of follow-up. The other two $(33.3 \%$ ) patients were retreated three (at weeks 16, 36, and 64 ) and four times (at weeks $8,28,36$, and 56) with a total of 80 and 71 weeks' follow-up, respectively (Table 2).

Regarding BCVA, $33.3 \%$ of patients gained between 19 to 21 letters of BCVA at the end of follow-up. The mean final BCVA was $0.58 \pm 0.3$ (decimal ETDRS equivalent). No patient experienced loss of BCVA during the study period. There was a statistically significant difference between baseline and final BCVA after intravitreal ranibizumab $(P=0.046$, Table 2).

The mean final central macular thickness in the study eyes was $273.50 \pm 12.74 \mu \mathrm{m}$. The median decrease in central macular thickness from baseline at the end of follow-up was $21 \mu \mathrm{m}(P=0.18)$. Only one $(16.6 \%)$ eye showed a minimal increase in central macular thickness of $2 \mu \mathrm{m}$; the other five $(83.3 \%)$ patients showed a mean decrease in central macular thickness of $17.6 \pm 13.2 \mu \mathrm{m}$. All these changes were not statistically significant. However, there was a positive correlation between intraretinal fluid by optical coherence tomography and improved BCVA after intravitreal ranibizumab. The patient with the better visual outcome (subject 3), had a BCVA improvement from 20/50 to 20/20, with a higher decrease in central macular thickness from 315 to $279 \mu \mathrm{m}$ (Figures 1 and 2).

We evaluated changes in visual symptoms in terms of persistence or recurrence of metamorphopsia. All patients examined with the red-lined black Amsler grid showed disappearance of metamorphopsia after the first intravitreal ranibizumab injection. The disappearance of metamorphopsia was independent of whether there was an improvement or not in BCVA. There was no recurrence of metamorphopsia during the follow-up period.

\section{Discussion}

In this prospective, single-center, uncontrolled, interventional pilot study, six eyes (from six patients) with drusenoid pigment epithelial detachment with a visual acuity of 20/63 to $20 / 100$ and no evidence of choroidal neovascularization in age-related macular degeneration were given a mean of three intravitreal ranibizumab injections and were followed for a mean of $66.67 \pm 10.3$ weeks. One third of the eyes

Table 2 Final visit characteristics of patients undergoing intravitreal ranibizumab treatment

\begin{tabular}{|c|c|c|c|c|c|c|c|}
\hline \multirow[t]{2}{*}{ Subject } & \multicolumn{3}{|c|}{ Final BCVA } & \multirow[t]{2}{*}{ CMT } & \multirow[t]{2}{*}{ Visual symptoms } & \multirow{2}{*}{$\begin{array}{l}\text { Follow-up time } \\
\text { (weeks) }\end{array}$} & \multirow[t]{2}{*}{ Treatments (n) } \\
\hline & Snellen & Letters & Decimal & & & & \\
\hline I & $20 / 63$ & 29 & 0.32 & 278 & None & 58 & 3 \\
\hline 2 & $20 / 25$ & 47 & 0.80 & 263 & None & 52 & 2 \\
\hline 3 & $20 / 20$ & 55 & 1.00 & 279 & None & 66 & I \\
\hline 4 & $20 / 32$ & 44 & 0.63 & 275 & None & 73 & 3 \\
\hline 5 & $20 / 40$ & 38 & 0.50 & 255 & None & 80 & 4 \\
\hline 6 & $20 / 100$ & 19 & 0.20 & 291 & None & 71 & 5 \\
\hline
\end{tabular}

Abbreviations: BCVA, best-corrected visual acuity; CMT, central subfield thickness. 


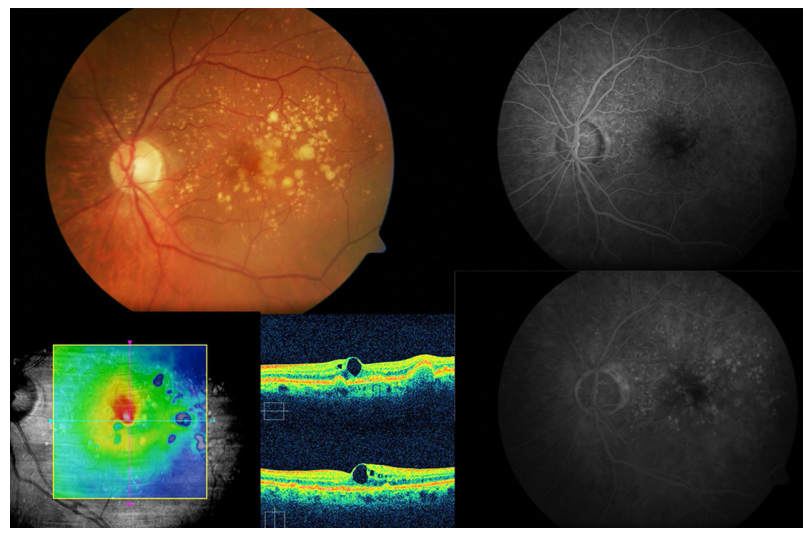

Figure I Subject 3: Baseline visit. A 67-year-old male complained of blurred vision on his left eye. Retinography demonstrates soft confluent drusen within the macular area (top left). Best-corrected visual acuity was 20/50. Optical coherence tomography revealed a drusenoid pigment epithelial detachment, and microcystic hyporreflective spaces within the neurosensory retina and an elevated retinal map (bottom left). Fluorescein angiography did not show any choroidal neovascularization associated (top and bottom right).

gained between 19 and 21 letters of BCVA, with a median decrease in central macular thickness of $21 \mu \mathrm{m}$. There was a statistically significant difference between baseline and final BCVA. Metamorphopsia disappeared completely after the first injection in all subjects, with no further recurrences. No patient developed choroidal neovascularization or atrophic changes.

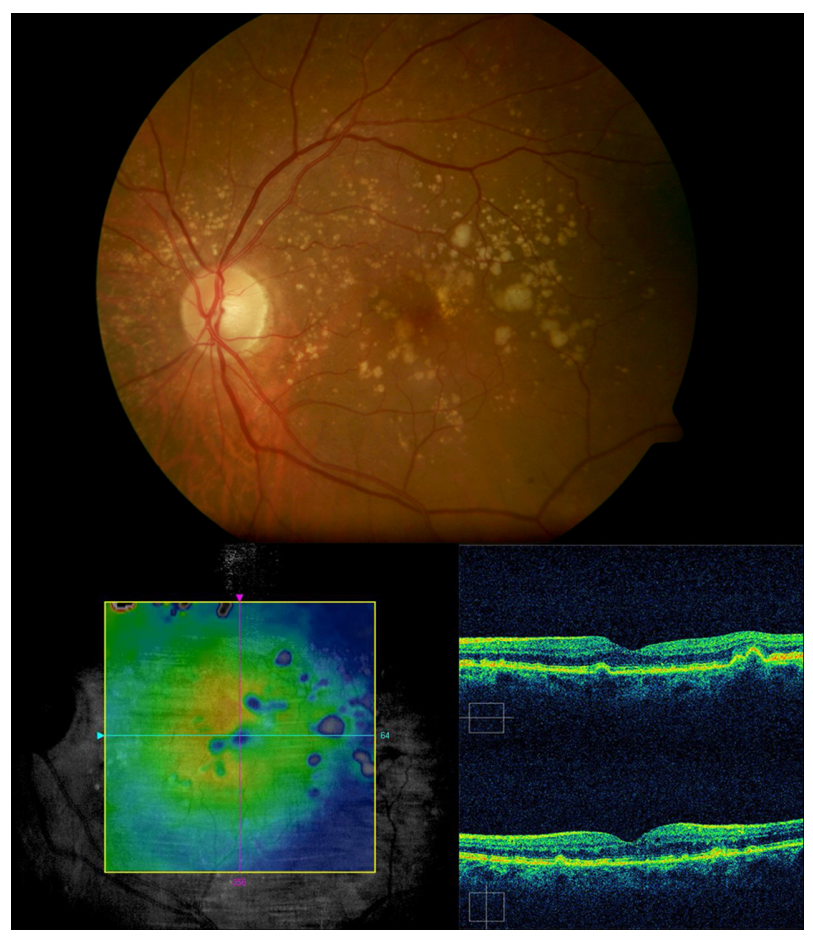

Figure 2 Subject 3: Final visit. Retinal pigment epithelium returned to a normal contour and no fluid was evident within the retina 66 weeks after a single injection of intravitreal ranibizumab (top and bottom). Best-corrected visual acuity improved to $20 / 20$ and remained stable through the follow-up period. No visual complaint was referred.
Drusenoid pigment epithelial detachment has a particular evolution and potential risks for severe loss of visual acuity, and it should be considered as a subgroup of age-related macular degeneration. The natural history has been defined as progression to persistent drusenoid pigment epithelial detachment, geographic atrophy, or choroidal neovascularization. ${ }^{18,19}$ However, no treatment has been established for drusenoid pigment epithelial detachment. Antivascular endothelial growth factor therapies ${ }^{15,16}$ have shown variable anatomical and visual outcomes.

Intravitreal ranibizumab seems to be beneficial in patients with drusenoid pigment epithelial detachment, especially when intraretinal fluid is present by optical coherence tomography. The exact mechanism by which antivascular endothelial growth factor therapies show promising outcomes is still unknown. In addition, none of our patients developed choroidal neovascularization or geographic atrophy. In a retrospective review, the risk of developing choroidal neovascularization in drusenoid pigment epithelial detachment was determined to be $11 \%$ at three years, $23 \%$ at five years, and $25 \%$ after 10 years. ${ }^{7}$ A recent report from the Age-Related Eye Disease Study group ${ }^{8}$ showed that $376(7.9 \%)$ of the 4757 patients included in the study presented with clinical features of drusenoid pigment epithelial detachment; after five years of follow-up, the incidence of choroidal neovascularization increased from $9 \%$ to $25 \%$ of these eyes, whereas the incidence of geographic atrophy increased from $0.3 \%$ to $5 \%$ of them. In conclusion, the total proportion of eyes with advanced age-related macular degeneration increased from $9 \%$ to $48 \%$, suggesting that drusenoid pigment epithelial detachment is an independent risk factor for advanced age-related macular degeneration. Despite the short-term follow-up (mean 66.67 weeks) and the limited number of eyes included in our study, according to these data, we should have found some degree of loss of visual acuity as a consequence of atrophic or neovascular changes, although the lack of a control group in the present study makes it impossible to offer conclusive data.

In summary, intravitreal ranibizumab demonstrated anatomic and functional benefit in patients with symptomatic drusenoid pigment epithelial detachment without choroidal neovascularization in age-related macular degeneration. Further long-term, randomized, controlled trials should be performed to confirm our preliminary results in order to provide us with some guidelines to treat these drusenoid pigment epithelial detachments before they progress to atrophic or neovascular changes within the foveal area where they are located and, therefore, prevent the visual loss associated with this phenomenon. 


\section{Disclosure}

The authors report no conflicts of interest in this work.

\section{References}

1. Casswell AG, Kohen D, Bird AC. Retinal pigment epithelium detachments in the elderly: Classification and outcome. Br JOphthalmol. 1985;69:397-403.

2. Hartnett ME, Weiter JJ, Garsd A, Jalkh AE. Classification of pigment epithelial detachments associated with drusen. Graefes Arch Clin Exp Ophthalmol. 1992;230:11-19.

3. Sarks SH. Ageing and degeneration in the macular region: A clinicopathological study. Br J Ophthalmol. 1976;60:324-341.

4. Bressler NM, Silva JC, Bressler SB, Fine SL, Green WR. Clinicopathologic correlation of drusen and retinal pigment epithelial abnormalities in agerelated macular degeneration. Retina. 1994;14:130-142.

5. Spraul CW, Grossniklaus HE. Characteristics of drusen and Bruch's membrane in post-mortem eyes with age-related macular degeneration. Arch Ophthalmol. 1997;115:267-273.

6. Pauleikhoff D, Löffert D, Spital G, et al. Pigment epithelial detachments in the elderly: Clinical differentiation, natural course and pathogenic implications. Graefes Arch Clin Exp Ophthalmol. 2002;240:533-538.

7. Roquet W, Roudot-Thoraval F, Coscas G, Soubrane G. Clinical features of drusenoid pigment epithelial detachment in age related macular degeneration. Br J Ophthalmol. 2004;88:638-642.

8. Cukras C, Agrón E, Klein ML, et al. Natural history of drusenoid pigment epithelial detachment in age-related macular degeneration: Age-Related Eye Disease Study Report No. 28. Ophthalmology. 2010;17:489-499.

9. Age-Related Eye Disease Study Research Group. A randomized, placebocontrolled, clinical trial of high-dose supplementation with vitamins $\mathrm{C}$ and $\mathrm{E}$, beta caroten, and zinc for age-related macular degeneration and vision loss: AREDS Report No. 8. Arch Ophthalmol. 2001;119:1417-1436.
10. Figueroa MS, Regueras A, Bertrand J. Laser photocoagulation to treat macular soft drusen in age-related macular degeneration. Retina. 1994; 14:391-396

11. Frennesson C, Nilsson SE. Prophylactic laser treatment in early agerelated maculopathy reduced the incidence of exudative complications. Br J Ophthalmol. 1998;82:1169-1174.

12. Macular Photocoagulation Study Group. Argon laser photocoagulation for neovascular maculopathy: Five-year results from randomized clinical trials. Arch Ophthalmol. 1991;109:1109-1114.

13. Olk RJ, Friberg TR, Stickney KL, et al. Therapeutic benefits of infrared (810-nm) diode laser macular grid photocoagulation in prophylactic treatment of nonexudative age-related macular degeneration: Two-year results of a randomized pilot study. Ophthalmology. 1999;106: 2082-2090.

14. Lee NY, Kim KS. Photodynamic therapy treatment for eyes with drusenoid pigment epithelium detachment. Korean J Ophthalmol. 2008; 22:194-196

15. Querques G, Bux AV, Delle Noci N. Foveal geographic atrophy following intravitreal pegaptanib sodium (Macugen) for drusenoid pigment epithelium detachment. Eur J Ophthalmol. 2009;19:890-893.

16. Krishnan R, Lochhead J. Regression of soft drusen and drusenoid pigment epithelial detachment following intravitreal anti-vascular endothelial growth factor therapy. Can J Ophthalmol. 2010;45:83-84.

17. Díaz-Llopis M, Cervera E, Amselem L, Udaondo P, Salom D, Montero J. Amsler grid versus near acuity and reading vision chart: Early selfdiagnosis in neovascular age-related macular degeneration. Arch Soc Esp Oftalmol. 2008;83:578-579. [Spanish].

18. Sarks JP, Sarks SH, Killingsworth MC. Evolution of soft drusen in age-related macular degeneration. Eye. 1994;8:269-283.

19. Abdelsalam A, Del Piore L, Zarbin MA. Drusen in age-related macular degeneration, natural course, and laser photocoagulation-induced regresión. Surv Ophthalmol. 1999;44:1-29.
Clinical Ophthalmology

\section{Publish your work in this journal}

Clinical Ophthalmology is an international, peer-reviewed journal covering all subspecialties within ophthalmology. Key topics include: Optometry; Visual science; Pharmacology and drug therapy in eye diseases; Basic Sciences; Primary and Secondary eye care; Patient Safety and Quality of Care Improvements. This journal is indexed on PubMed

Submit your manuscript here: http://www.dovepress.com/clinical-ophthalmology-journal

\section{Dovepress}

Central and CAS, and is the official journal of The Society of Clinical Ophthalmology (SCO). The manuscript management system is completely online and includes a very quick and fair peer-review system, which is all easy to use. Visit http://www.dovepress.com/testimonials. php to read real quotes from published authors. 